\title{
Evaluation of Postoperative Analgesic Consumption After Emergency and Elective Cesarean Section
}

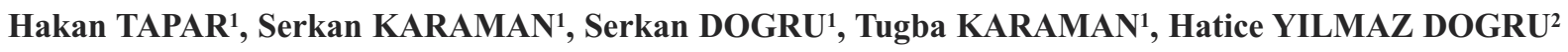 \\ Tokat, Turkey
}

\begin{abstract}
OBJECTIVE: This study compares post-operative pain and analgesic consumption among patients who have undergone either an emergent or elective caesarean section.

STUDY DESIGN: A total of 115 patients, comprised of 48 emergency caesarean section and 67 elective caesarean section patients, were enrolled in this prospective study. Pain intensity was evaluated with a numeric pain scale in the $1 \mathrm{st}, 2^{\text {nd }}, 6^{\text {th }}, 12^{\text {th }}$, and $24^{\text {th }}$ post-operative hours and total post-operative tramadol consumption within 24 hours was recorded for each patient.
\end{abstract}

RESULTS: Total tramadol consumption for emergency caesarean section patients under general anesthesia was $222.91 \pm 56.52 \mathrm{mg}$ and for elective caesarean section patients under general anesthesia was $181.71 \pm 55.38 \mathrm{mg}(p<0.05)$. In patients under spinal anesthesia, total tramadol consumption was found to be $169.58 \pm 59.52 \mathrm{mg}$ and $160.62 \pm 70.47 \mathrm{mg}$ in emergency and elective cases respectively $(p>0.05)$.

CONCLUSION: Analgesic consumption for emergency caesarean section patients under general anesthesia was observed to be high.

Keywords: Analgesia, Caesarean section, Pain

Gynecol Obstet Reprod Med 2019;25(2):70-73

\section{Introduction}

Pain levels ranging from intermediate to severe were observed during the post-operative period. Acute post-operative pain is a medication that should be addressed (1) because of the increasing frequency of chronic pain and effective management of post-operative pain is an important issue for the patients' quality of life (2). Thus, it is important that both the surgeons and the anesthesiologist should be active, in management of

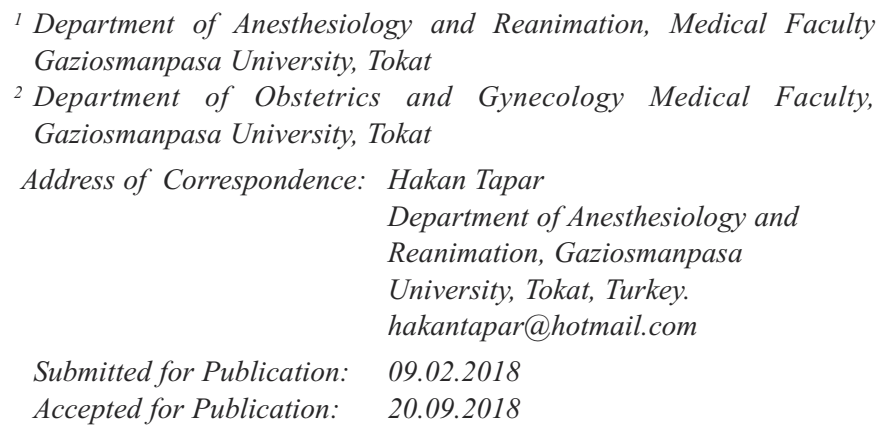

ORCID IDs of the authors:

H.T.: 0000-0001-7625-0864, S.K.: 0000-0003-0534-629X

S.D.: 0000-0003-1400-7628, T.K.: 0000-0002-5935-3471

H.Y.D.: 0000-0003-3431-2072

\begin{tabular}{|c|c|}
\hline Quick Response Code: & Access this article online \\
\cline { 2 - 2 } & $\begin{array}{l}\text { Website: www.gorm.com.tr } \\
\text { e- mail: info@gorm.com.tr }\end{array}$ \\
\cline { 2 - 3 } & DOI:10.21613/GORM.2018.778 \\
\cline { 2 - 3 } &
\end{tabular}

How to cite this article: Tapar H. Karaman S. Dogru S. Karaman T. Yılmaz Dogru H. Evaluation of Postoperative Analgesic Consumption After Emergency and Elective Cesarean Section. Gynecol Obstet Reprod Med $2019 ; 25(2): 70-73$ post-operative pain. Control of acute post-operative pain following a caesarean section differs from other surgical interventions, as the mother is in an expectation of being healthy and she wants to feed the new-born baby as soon as possible (3). Additionally, anxiety and depressive disorders may be present in the mother during the post-operative period (4).

Despite recent developments in caesarean section pain management, it is still ineffective in many patients, and there is a strong need for parameters that can be used to predict the intensity of post-operative pain after caesarean section (5).

Our aim in this study is to evaluate the analgesic consumption of patients who underwent a caesarean section under either emergency or elective conditions. The findings of this study can contribute to pain management after emergency and elective caesarean sections.

\section{Material and Method}

After obtaining approval from the ethical committee (Ethics committee no: 13-KAEK-226) and grant submission to clinicaltrials.gov (Grant number: NCT02332395), patients who had an emergency or elective caesarean section between January 2014 and January 2015 were included in the study in two groups. Patients in the groups were over 18 years of age, had no clinical contraindications to spinal blockade and general anesthesia and were assessed as ASA I or II under the American Society of Anesthesiologist's physical status classification system. Patients were excluded from the study if they had chronic pain, psychiatric illness, an inability to express 
themselves or did not want to participate in the study. All other patients who met the inclusion criteria took part in the study during the study period. Patients were divided into two main groups according to whether they had an emergency or elective caesarean section; these two groups were further sorted into two subgroups according to whether they were administered spinal or general anesthesia. Fetal distress, placenta previa, placental abruption, failure to induce labor, severe pre-eclampsia, eclampsia and cord prolapse were considered emergency caesarean section indications, while previous caesarean delivery, cephalopelvic disproportion, fetal macrosomia and multiple pregnancies were accepted as indications of elective caesarean section.

Patients were informed of the benefits of both general and spinal anesthesia. The type of anesthesia to be administered was selected by the patient unless a medical contraindication was present. In all other cases, the anesthesiologist physician decided the type of anesthesia. General anesthesia was induced with rocuronium bromide 0.6 $\mathrm{mg} / \mathrm{kg}$ and propofol $2 \mathrm{mg} / \mathrm{kg}$ intravenous (IV). After the placenta was delivered, 50 micrograms of fentanyl were administered. As volatile anesthetic, sevoflurane 2 MAC and $50 \% / 50 \% \mathrm{O}_{2} /$ air mixture was administered. In the intra-operative period, tramadol $1 \mathrm{mg} / \mathrm{kg}$ was administered for postoperative analgesia. Spinal anesthesia was administered by injecting $0.5 \% 12.5 \mathrm{mg}$ intrathecal heavy bupivacaine with a $25 \mathrm{G}$ Quincke tip needle, in the sitting position under sterile conditions. All patients were routinely given $10 \mathrm{~mL} / \mathrm{kg}$ Ringer's lactate solution intravenously to prevent hypotension associated with sympathetic blockade.

The Numeric Rating Scale (NRS) has frequently been used in clinical trials to evaluate pain intensity (6). In this study, patients were asked to evaluate their post-operative pain ( 0 : no pain; 1 to 2 : mild pain; 3 to 4: moderate pain; 5 to 6 : severe pain; 7 to 8: very severe pain; 9 to 10 : most severe pain), and pain intensity within the post-operative first, second, sixth, twelfth and twenty-fourth hours was evaluated using this scale.

Patients were connected to a patient- controlled analgesia (PCA) device immediately after being taken to the recovery room and were asked to press the PCA button when their pain severity was NRS $\geq 4$. The PCA device was programmed to give a bolus dose of $20 \mathrm{mg}$ tramadol hydrochloride whenever the button was pressed, with a lock-out time of $15 \mathrm{~min}$ utes. The total amount of analgesic used was recorded at the end of the study period. Pain intensity and patients' total post-operative analgesic consumption were evaluated.

\section{Statistical analysis}

Kolmogorov-Smirnov test was performed in order to assess the distribution of data. Quantitative data were presented as means and standard deviation and qualitative data as frequency and percentage. Associations were performed using the Pearson correlation coefficient ( $r$ ). Comparisons of the qualitative data were conducted with the chi-square test and comparisons of the quantitative data were performed using the Mann-Whitney $U$ test as the data were not normally distributed. The analysis was conducted using the Statistical Package for Social Sciences (SPSS Inc., Chicago, IL) program, version 20.0. The statistical significance for all analyses was set at $p<0.05$.

\section{Results}

A total of 115 patients, comprising 48 emergency caesarean section patients (27 underwent general anesthesia and 21 underwent spinal anesthesia) and 67 elective caesarean section patients (31 underwent general anesthesia and 36 underwent spinal anesthesia) were enrolled in this prospective study (Figure 1). The main demographic features, such as age, weight, height, body mass index (BMI) and ASA score are shown in table I.

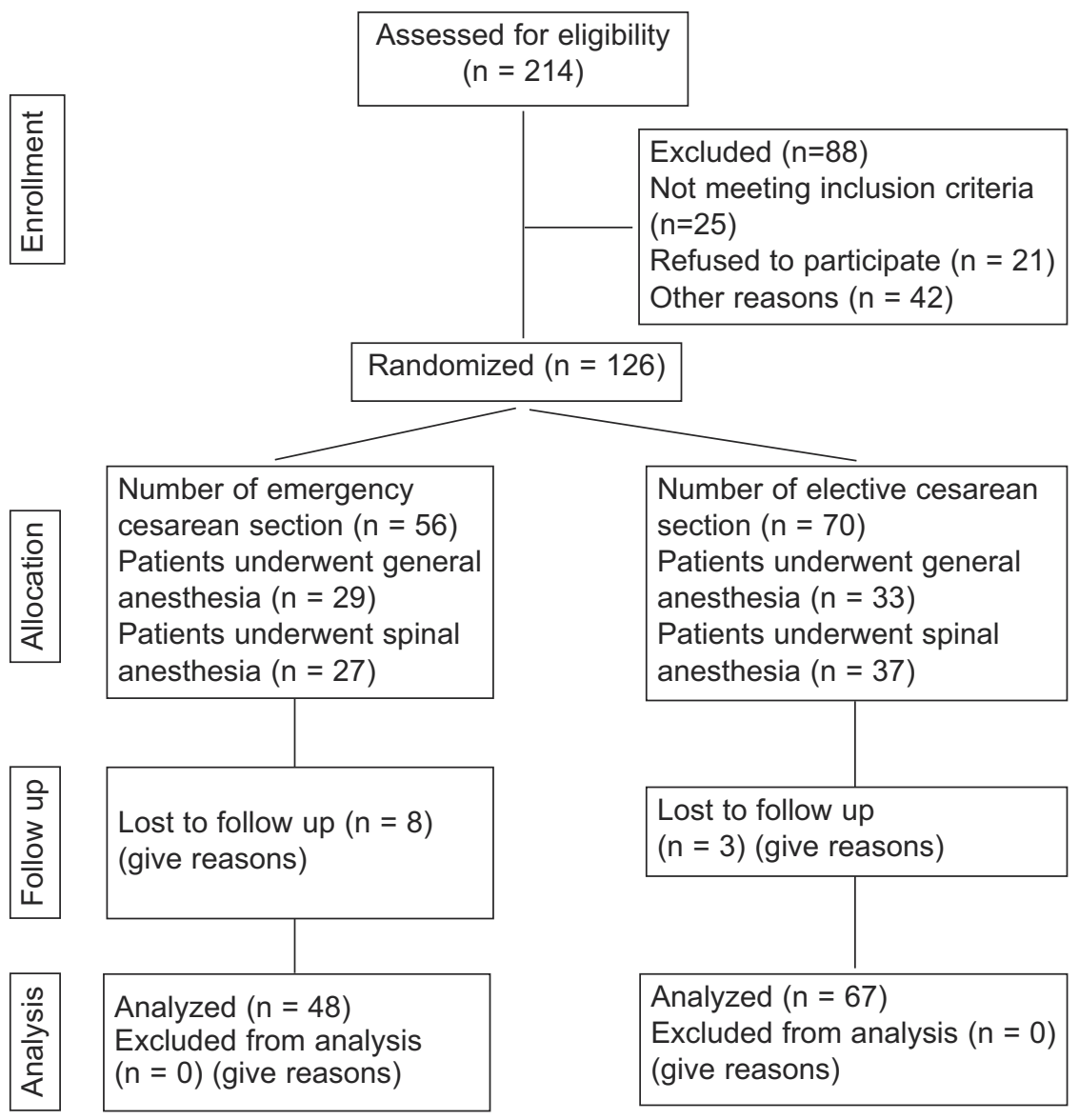

Figure 1: Flow chart 
Table I: Demographic characteristics

\begin{tabular}{lccc}
\hline & Emergency (Mean \pm SD) & Elective (Mean \pm SD) & $p$ \\
\hline Age $^{\mathrm{a}}$ (years) & $28.91 \pm 6.42$ & $28.37 \pm 5.07$ & 0.827 \\
Weight $(\mathrm{kg})$ & $74.14 \pm 9.64$ & $77.38 \pm 13.20$ & 0.295 \\
Height $(\mathrm{cm})$ & $162 \pm 5.27$ & $161.25 \pm 8.15$ & 0.884 \\
BMIb $^{\left.\mathrm{kg} / \mathrm{m}^{2}\right)}$ & $28.25 \pm 3.44$ & $29.81 \pm 4.94$ & 0.114 \\
ASA I/II & $33 / 15$ & $48 / 19$ & 0.738 \\
\hline
\end{tabular}

BMI: Body mass index, a: Values are given as mean $\pm S D$ unless indicated otherwise, $b$ : Calculated as weight in kilograms divided by the square of height in meters

The total tramadol consumption of emergency caesarean section patients was $196.25 \pm 63.43 \mathrm{mg}$ and of elective caesarean section patients was $171.64 \pm 63.45 \mathrm{mg}$ ( $p=0.041$; Table II). The total tramadol consumption of emergency caesarean patients under general anesthetic was significantly higher $(222.91 \pm 56.52 \mathrm{mg})$ than that of elective caesarean patients under general anesthetic $(181.71 \pm 55.38 \mathrm{mg} ; p=0.008)$. The total tramadol consumption of emergency caesarean patients under spinal anesthetic was similarly found to be higher $(169.58 \pm 59.52 \mathrm{mg})$ than that of elective caesarean patients under spinal anesthetic (160.62 $\pm 70.47 \mathrm{mg} ; p=0.521$; Figure 2).

Figure 2: Total tramadol consumption in emergency and elective cesarean section

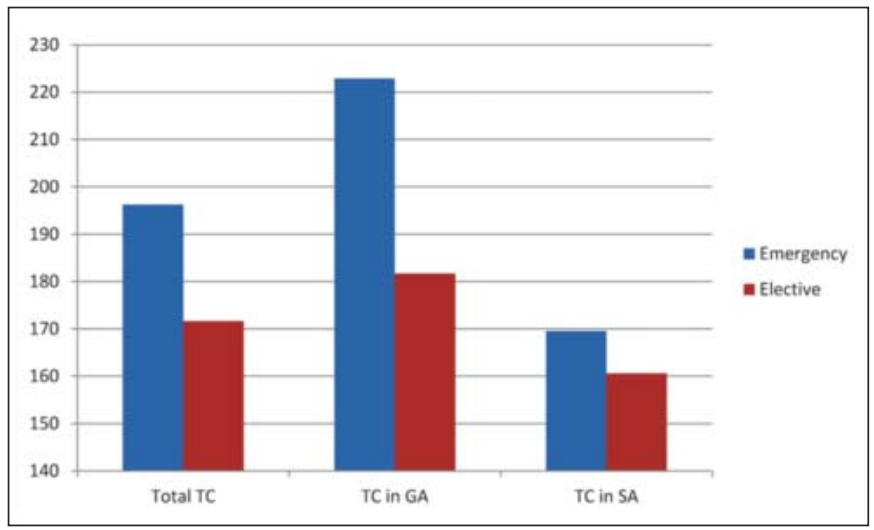

Total TC: Total tramadol consumption( $p=0.041)$, TC in GA: Tramadol concumption in general anesthesia $(p=0.008)$, TC in SA: Tramadol consumption spinal anesthesia $(p=0.521)$.

Differences in NRS values between emergency and elective caesarean section patients were found to be statistically significant (2.56 \pm 0.87 and $2.34 \pm 1.12$ respectively, $p=0.039)$.

\section{Discussion}

In this study, postoperative analgesic consumption in pa- tients who had an emergency caesarean section under general anesthetic was found to be higher than that of patients who had an elective caesarean section.

The existence of preoperative pain was found to be an important predictor for the intensity of post-operative pain (7) and increased post-operative analgesic consumption (8). Preoperative pain has been demonstrated to be a predictor of post-operative analgesic consumption, though the mechanism of this effect is not yet completely understood (9). In our observations, emergency surgical indications, including caesarean sections, cause more preoperative pain in patients. This may have affected analgesic consumption in cases of emergency caesarean section.

Preoperative pain and anxiety were identified as the most common causes of post-operative pain and analgesic consumption (6). Anxiety is found to be more pronounced in patients requiring emergency surgical intervention (10), decreases the pain threshold and exaggerates perceptions of experienced pain (11). In an observational study on post-operative morphine requirement, an emergency surgical intervention increased morphine consumption and was linked to increased patient anxiety levels in emergency surgical interventions (12).

Educating patients was found to be more effective in reducing anxiety than benzodiazepines, but in emergency cases there is seldom sufficient time in which to inform patients (13). Preoperative anxiety and post-operative analgesic consumption might, therefore, be expected to be higher in emergency caesarean section patients than in elective caesarean section patients (14).

Psychological and behavioral factors are often neglected in post-operative pain management (6). Emergency caesarean section patients experience more postnatal stress disorders and

Table II: The mean numeric rating scale and total analgesic consumption between groups

\begin{tabular}{lccc}
\hline & Emergency (Mean \pm SD) & Elective (Mean \pm SD) & $p$ \\
\hline NRS & $2.56 \pm 0.87$ & $2.34 \pm 1.12$ & 0.039 \\
GA-NRS & $1.6 \pm 0.6$ & $1.42 \pm 0.65$ & 0.049 \\
SA-NRS & $2.65 \pm 1.00$ & $2.22 \pm 0.73$ & 0.038 \\
TTC & $196.25 \pm 63.43$ & $171.64 \pm 63.45$ & 0.041 \\
GA-TTC & $222.91 \pm 56.52$ & $181.71 \pm 55.38$ & 0.008 \\
SA-TTC & $169.58 \pm 59.52$ & $160.62 \pm 70.47$ & 0.157 \\
\hline
\end{tabular}

NRS: Numeric rating scale, GA-NRS: General anesthesia numeric rating scale, SA-NRS: Spinal anesthesia numeric rating scale, TTC: Total tramadol consumption, GA-TTC: General anesthesia total tramadol consumption, SA-TTC: Spinal anesthesia total tramadol consumption 
mentally negative experiences compared to elective caesarean section or normal delivery patients (4). We think that patient education, good communication and, if not contraindicated, use of anxiolytics in the post-operative period may help prevent anxiety-induced post-operative pain, but it is difficult to prepare emergency caesarean section patients in the preoperative period. Preoperative anxiety and negative feelings and ideas in the post-operative period may have affected the analgesic consumption of emergency caesarean section patients.

In our study, the total tramadol consumption of emergency caesarean section patients under general anesthetic was found to be higher than that of elective caesarean section patients. No difference in total tramadol consumption was observed between emergency and elective caesarean section patients who underwent spinal anesthesia. In a study comparing spinal and general anesthesia in caesarean section patients, the group with spinal anesthesia experienced less post-operative pain and analgesic consumption (16). In another study, regional anesthesia was found to prompt a lower pain scale when compared to the effects of general anesthesia (17). We think that the effectiveness of spinal anesthesia independent from the patient and the illness and prolonged post-operative painkilling effects of spinal anesthesia may contribute to the above-mentioned findings.

This study has some limitations. Although increased analgesic consumption in emergency patients was specifically linked to preoperative anxiety in our study, the study could be criticized for not having carried out an evaluation of preoperative anxiety.

In conclusion, we found that emergency caesarean sections increase post-operative analgesic consumption. Some factors, such as preoperative pain, may have affected analgesic consumption in emergency caesarean section patients.

: Acknowledgement: This article was presented as an oral paper at the Turkish anesthesiology and reanimation congress (2017).

Conflict of interest statement: The authors reported no conflict interest.

Funding: None

\section{References}

1. Sommer M, de Rijke JM, van Kleef M, Kessels AG, Peters ML, Geurts JW. et al. Predictors of acute postoperative pain after elective surgery. Clin J Pain. 2010;26(2): 87-94.

2. Gagliese L, Katz J. Age differences in postoperative pain are scale dependent: a comparison of measures of pain intensity and quality in younger and older surgical patients. Pain. 2003;103(1-2):11-20.

3. de Brito Cançado TO, Omais M, Ashmawi HA, Torres ML. Chronic pain after cesarean section. Influence of anesthetic/surgical technique and postoperative analgesia. Rev Bras Anestesiol. 2012;62(6):762-74.

4. Ryding EL, Wijma K,Wijma B. Psychological impact of emergency cesarean section in comparison with elective cesarean section, instrumental and normal vaginal delivery. J Psychosomc Obstet Gynaecol. 1998;19(3):135-44.

5. Strulov L, Zimmer EZ, Granot M, Tamir A, Jakobi P, Lowenstein L. Pain catastrophizing, response to experimental heat stimuli,and post-cesarean section pain. J Pain. 2007;8(3):273-9.

6. Ip HY, Abrishami A, Peng PW, Wong J, Chung F. Predictors of postoperative pain and analgesic consumption: a qualitative systematic review. Anesthesiol. 2009;111(3):657-77.

7. Rudin A, Wolner-Hanssen P, Hellbom M, Werner MU. Prediction of postoperative pain after a laparoscopic tubal ligation procedure. Acta Anaesthesiol Scand. 2008;52(7): 938-45.

8. Taenzer P, Melzack R, Jeans ME. Influence of psychological factors on postoperative pain, mood and analgesic requirements. Pain. 1986;24(3):331-42.

9. Kalkman CJ, Visser K, Moen J, Bonsel GJ, Grobbee DE, Moons KG. Preoperative prediction of severe postoperative pain. Pain. 2003;105(3):415-23.

10. Karanc1 AN, Dirik G. Predictors of pre- and postoperative anxiety in emergency surgery patients. J Psychosom Res. 2003;55(4):363-9.

11. Rhudy JL, Meagher MW. Fear and anxiety: Divergent effects on human pain thresholds. Pain. 2000;84(1):65-75.

12. Dahmani S, Dupont H, Mantz J, Desmonts JM, Keita H. Predictive factors of early morphine requirements in the post-anesthesia care unit (PACU). Br J Anaesth. 2001; 87(3):385-9.

13. Levenson J.L, MD. Psychiatric Issues in Surgical Patients Part I: General Issues. Pri Psychiat. 2007;14(5):35-39.

14. Main CJ, Spanswick CC, Watson P. The nature of disability. In: Main CJ, Spanswick CC (eds). Pain Management: an interdisciplinary approach. Edinburgh: Churchill Livingstone; 2000, p 89-106.

15. Salmon P, Drew NC. Multidimensional assessment of women's experience of childbirth: relationship to obstetric procedure, antenatal preparation and obstetric history. J Psychosom Res. 1992;36(4):317-27.

16. Fabris KL, Maretic A. Effects of general anesthesia versus spinal anesthesia for caesarean section on postoperative analgesic consumption and postoperative pain. Period Biol. 2009;111(2):251-55.

17. Liu SS, Strodtbeck WM, Richman JM, Wu CL. A comparison of regional versus general anesthesia for ambulatory anesthesia: a meta-analysis of randomized controlled trials. Anesth Analg. 2005; 101(6):1634-42. 